\title{
Overdose Research: 15 Years Later
}

\author{
Phillip O. Coffin • Josiah D. Rich
}

Published online: 8 January 2019

(C) The New York Academy of Medicine 2019

The earliest literature on opioid overdose emerged in the 1970s, with prophetic papers discussing issues that remain unresolved today [1]. Edward M. Brecher refuted the term "overdose," emphasizing polydrug toxicity and noting that the event took time, with opportunity for intervention [2]. These results were confirmed by forensic work and, later, through interviews with people who use drugs (PWUD) [3-9] and others who witnessed overdoses $[10,11]$. Study of overdose decedents through "psychological autopsies" identified older age and injection as prime risk factors, with suicide less common [10, 11], results that have also held up [12]. By the 1990s, overdose research focused on surveys of PWUD and analyses of ambulance and medical examiner data. Event-level analyses found that opioid overdose usually happens in the presence of others $[8$, 13-16] and is often managed without medical assistance due to concerns about police involvement $[14,17]$. These data supported naloxone distribution programs, which have since become a central element of any overdose prevention effort, as a way to leverage witnesses to an overdose that might not otherwise receive timely medical attention.

P. O. Coffin $(\bowtie)$

University of California, San Francisco, San Francisco, CA, USA e-mail: Phillip.Coffin@ucsf.edu

J. D. Rich

Brown University, Providence, RI, USA

e-mail: jrich@lifespan.org
The first issue of the Journal of Urban Health dedicated to overdose was released in 2003. Among the innovative papers included in that issue was a geocoding analysis of overdose mortality in San Francisco [13] demonstrating that overdose mortality was focused in neighborhoods with single-room occupancy (SRO) hotel units, whereas overdose prevention activities were based in a neighborhood of young people who inject drugs (PWID). These findings not only added to our understanding of how social isolation may contribute to the older age of overdose decedents relative to overdose survivors, but also directly resulted in a shift and expansion of overdose prevention activities to SRO hotels and neighborhoods. That manuscript was a prime example of how science can change public policy.

Nonetheless, implementing overdose prevention in SRO hotels has proven challenging. Management can be resistant to overdose prevention programming, comorbidities among older residents may increase the likelihood of mortality in the event of an overdose, and residents residents who use drugs often do so in isolation. The concern of overdose mortality in SRO hotels has only increased due to the critical housing shortage afflicting many cities throughout North America. In this issue of the Journal, Bardwell et al. describe the Tenant Overdose Response Organizers (TORO) program, an SRO-based lay naloxone responder program in Vancouver [18]. TORO benefited from a structured program and by empowering peers, although tenants in some facilities continued to face resistance from management 
and challenges caused by a deteriorating physical plant. While some facilities were highly supportive of the intervention, tenants in other buildings resisted participation or faced threats from management due to the association of overdose prevention with drug use. Tenants also faced burnout due to the frequency and traumatic nature of overdose events, a finding reported previously among PWUD who carry naloxone [19]. While further innovation, including technology, is likely needed to address the isolation of many marginally housed individuals, the TORO program should be an example for other cities as we try to address the comorbid overdose and housing crises.

Providing naloxone to PWUD, as seen in TORO, can be empowering. Rather than merely a tool for reversing an overdose, several studies have suggested that receiving naloxone may be associated with reduced illicit opioid use [20] or reduced opioid-related emergency department visits [21]. Community distribution programs, which provide naloxone at no charge and usually with no identifying information from the recipient, have proven the most effective method of delivering naloxone to those most likely to subsequently use the medication [22]. As Rowe et al. demonstrate in this issue of the Journal [23], community distribution programs may also serve a surveillance role. In this paper, authors found that San Francisco's naloxone distribution program detected the emergence of fentanyl in the community through increased overdose reversals, without any increase in mortality. This use of an essentially peer-run intervention to identify drug trends in real time is an exciting and powerful application of existing services in the current crisis.

Innovative use of services can be extended to existing research methods, as Rudolph et al. demonstrate in their analysis of rural PWID networks and overdose risk in Appalachia [24]. Given that overdoses are rarely attended to by the person who overdosed, any overdose response intervention is in its nature dependent upon the network of the person suffering the overdose. The authors found that having overdose events in one's social network was more likely for participants who lived toward the center of town, were more central in the networks, and had attended an alcohol detoxification program. These types of results are useful not only to target naloxone provision if resources are limited, but also for potential intervention trials for which maximizing power is essential.
The fentanyl crisis has also required dramatic innovation in existing services. Scheuermeyer et al. describe the use of a trailer to manage presumed fentanyl overdose events in a high volume neighborhood [25]. They accepted patients who were fully alert and only $1.1 \%$ required subsequent transfer to the emergency department, suggesting that this level of interim care is remarkably safe. Not only is this a benefit for overburdened emergency systems, but it is likely a preferable system of care for patients. As emergency providers know well, patients who suffer an opioid overdose often do not want to be transported to the hospital. While there are no randomized trials, large epidemiologic studies strongly suggest that releasing patients who are fully alert is safe [26, 27], yet this practice may miss an opportunity to provide patients with related healthcare services. Scheuermeyer et al. found that $16 \%$ of patients seen at this interim level of care were started on treatment for opioid use disorder and the vast majority was provided with naloxone kits, important interventions that would not have been achieved if the patient had snuck out the backdoor of the ambulance on the way to the hospital.

As fentanyl expanded, it was rapidly noted to affect not only the street opioid market, but other drugs as well. Public health alerts have noted fentanyl in counterfeit pills, cocaine, methamphetamine, and other drugs [28]. The distribution of fentanyl tests trips to PWUD has demonstrated frequent presence of fentanyl or its analogues in these other street drugs [29]. Meanwhile, the opioid crisis has been complicated by rising rates of stimulant toxicity deaths, with some suggesting that these increases are a result of opioids [30]. The relationship between opioid overdose and stimulant use has long been recognized [31], yet we have not known if this association is due to physiologic properties of the drug classes or simply serves as a marker for more risky substance use behaviors. The current situation is further complicated by the entry of fentanyl into the drug market, sometimes as a contaminant, an adulterant, or wholesale replacement of the marketed product. Nolan et al. further discuss in this issue of the Journal, with their analysis of cocaine toxicity deaths in New York City [32]. Not only did they find that the vast majority of the increase in cocaine toxicity deaths also involved opioids, but $90 \%$ of that increase involved fentanyl. These results clearly establish that we cannot effectively respond to the opioid crisis without simultaneously addressing stimulant use. 
In fact, much of the effort in responding to the opioid crisis has been focused on addressing opioid prescribing by healthcare providers. Vast federal and state resources have been invested in controlled substance monitoring programs (CSMPs). These programs are frequently run by state departments of justice and serve a primary lawenforcement tool. The commonly used nomenclature "prescription drug monitoring program" is both a misnomer and a painful reminder that medical providers continue to lack the ability to see what prescription medications, besides controlled substances, our patients are taking. CSMPs are nevertheless useful tools for understanding opioid prescribing trends and what association these trends may have with overdose. In this issue of the Journal, Abbasi et al. linked CSMP, medical examiner, and electronic health record data in Illinois [32]. The authors determined that $30 \%$ of decedents had not received an opioid prescription in at least the past 6 yearsquite a long time frame that clearly sets these individuals apart from those receiving opioid prescriptions at the time of death. Decedents who had not received an opioid prescription were more likely to be Black, Latinx, or from Chicago, more likely to die from heroin or fentanyl as compared to prescription opioids, less likely to have been seen in the emergency department, and less likely to have received a diagnosis of or treatment for opioid use disorder. This is a critical reminder that a substantial portion of those being lost to the opioid crisis has limited contact with the healthcare system. Notwithstanding the benefits of expanded healthcare access under the Affordable Care Act, there remains an essential need for low-threshold, nonjudgmental, often anonymous, and peer-driven, services that reach out to people where they spend time.

Abbasi et al. remind us that overdose was a critical issue in urban areas long before the current crises - and will be long after. We have come a long way since Becher's first papers on the subject, but have only recently begun to develop the workforce needed to dig deep into understanding and preventing overdose and subsequent mortality. Methadone and buprenorphine maintenance treatment, provision of naloxone for lay administration, and supervised consumption services all have well-controlled, albeit largely observational, data demonstrating reductions in opioid overdose mortality. Injectable naltrexone [33] and some behavioral interventions [34, 35] likely also reduce opioid overdose, although confirmatory research is needed. Mathematical modeling of overdose has finally begun to gain traction [36], which is another sign of the growing workforce attending to the issue.
Yet, the current crises have challenged our best efforts. With over 72,000 deaths in 2017 and no evidence to date of a meaningful reduction in mortality, the overdose crisis is not only among the worst health crises to affect the USA [37], but also full of stark questions. We continue to not fully understand qualitative differences between nonfatal and fatal overdose events or why some individuals tend to overdose repeatedly. We have limited understanding of fatal stimulant toxicity events. More urgently, we are only now beginning to have a sense of the basic epidemiology of prescription opioid overdose and the event-level details of fentanyl overdose. Innovative methods such as those presented in this issue of the Journal, as well as other database linkage studies, clinical trials, and observational work in settings such as supervised consumption services, are proving vital to our response. Compared to just 63 scientific papers published in 2003 that addressed overdose, there were 345 published in 2017. We are hopeful that this effort can result not only in reduced overdose mortality today, but a new approach to substance use that respects individuals, attends to the harms of drugs rather than the perceived immorality of substance use, and holds addiction medicine to the same standards as other public health and medical disciplines.

Acknowledgements Preparation of this manuscript was supported by NIDA grant \#K24DA042720. Dr Rich's involvement in this issue was supported, in part, by grant P20 GM125507 from the National Institute of General Medical Studies of the National Institutes of Health. Dr Coffin's involvement in this issue was supported, in part, by grant K24DA042720 from the National Institute on Drug Abuse of the National Institutes of Health.

Publisher's Note Springer Nature remains neutral with regard to jurisdictional claims in published maps and institutional affiliations.

\section{References}

1. Darke S. Heroin overdose. Addiction. 2016;111(11):2060-3.

2. Brecher EM. The consumers union report on licit and illicit drugs. Boston: Little, Brown \& Co; 1972.

3. Monforte JR. Some observations concerning blood morphine concentrations in narcotic addicts. J Forensic Sci. 1977;22(4):718-24.

4. Darke S. Attacking overdose on the home front. Addiction. 1999;94(2):205-6. discussion 207

5. Darke S, Hall W, Weatherburn D, Lind B. Fluctuations in heroin purity and the incidence of fatal heroin overdose. Drug Alcohol Depend. 1999;54(2):155-61. 
6. McGregor C, Darke S, Ali R, Christie P. Experience of non-fatal overdose among heroin users in Adelaide, Australia: circumstances and risk perceptions. Addiction. 1998;93(5):701-11.

7. Darke S, Ross J, Hall W. Overdose among heroin users in Sydney, Australia: I. Prevalence and correlates of non-fatal overdose. Addiction. 1996;91(3):405-11.

8. Darke S, Ross J, Hall W. Overdose among heroin users in Sydney, Australia: II. Responses to overdose. Addiction. 1996;91(3):413-7.

9. Rosenman SJ. Subsequent deaths after attempted suicide by drug overdose in the western region of Adelaide, 1976. Med J Aust. 1983;2(10):496-9.

10. Manning FJ, Ingraham LH, DeRouin EM, Vaughn MS, Kukura FC, St Michel GR. Drug "overdoses" among U.S. soldiers in Europe, 1978-1979. II. Autopsies following deaths and near-deaths. Int J Addict. 1983;18(2):153-66.

11. Manning FJ, Ingraham LH. Drug "overdoses" among U.S. soldiers in Europe, 1978-1979. I. Demographics and toxicology. Int J Addict. 1983;18(1):89-98.

12. Heale P, Dietze P, Fry C. Intentional overdose among heroin overdose survivors. J Urban Health. 2003;80(2):230-7.

13. Davidson PJ, McLean RL, Kral AH, Gleghorn AA, Edlin BR, Moss AR. Fatal heroin-related overdose in San Francisco, 1997-2000: a case for targeted intervention. $J$ Urban Health. 2003;80(2):261-73.

14. Davidson PJ, Ochoa KC, Hahn JA, Evans JL, Moss AR. Witnessing heroin-related overdoses: the experiences of young injectors in San Francisco. Addiction. 2002;97(12):1511-6.

15. Seal KH, Kral AH, Gee L, Moore LD, Bluthenthal RN, Lorvick J, et al. Predictors and prevention of nonfatal overdose among street-recruited injection heroin users in the San Francisco Bay Area, 1998-1999. Am J Public Health. 2001;91(11):1842-6.

16. Ochoa KC, Hahn JA, Seal KH, Moss AR. Overdosing among young injection drug users in San Francisco. Addict Behav. 2001;26(3):453-60.

17. Tracy M, Piper TM, Ompad D, Bucciarelli A, Coffin PO, Vlahov D, et al. Circumstances of witnessed drug overdose in New York City: implications for intervention. Drug Alcohol Depend. 2005;79(2):181-90.

18. Bardwell G, Fleming T, Collins AB, Boyd J, McNeil R. Addressing intersecting housing and overdose crises in Vancouver, Canada: opportunities and challenges from a tenant-led overdose response intervention in single room occupancy hotels. J Urban Health. 2018. https://doi. org/10.1007/s11524-018-0294-y.

19. Wagner KD, Davidson PJ, Iverson E, Washburn R, Burke E, $\mathrm{Kral} \mathrm{AH}$, et al. "I felt like a superhero": the experience of responding to drug overdose among individuals trained in overdose prevention. Int J Drug Policy. 2014;25(1):157-65.

20. Seal KH, Thawley R, Gee L, et al. Naloxone distribution and cardiopulmonary resuscitation training for injection drug users to prevent heroin overdose death: a pilot intervention study. J Urban Health. 2005;82(2):303-11.

21. Coffin PO, Behar E, Rowe C, Santos GM, Coffa D, Bald M, et al. Nonrandomized intervention study of naloxone coprescription for primary care patients receiving longterm opioid therapy for pain. Ann Intern Med. 2016;165(4):245-52.

22. Rowe C, Santos M, Vittinghoff E, Coffin PO. Characteristics and predictors of naloxone recipients, refillers, and reversals in a community-based naloxone distribution program. Paper presented at: 2nd Conference on Overcoming Health Disparities in the Bay Area: Focus on HIV \& HCV; February 3, 2015; San Francisco, CA.

23. Rowe C, Wheeler E, Stephen Jones T, Yeh C, Coffin PO. Community-based response to fentanyl overdose outbreak, San Francisco, 2015. J Urban Health. 2018. https://doi. org/10.1007/s11524-018-0250-x.

24. Rudolph AE, Young AM, Havens JR. Using network and spatial data to better target overdose prevention strategies in rural Appalachia. J Urban Health. 2018. https://doi. org/10.1007/s11524-018-00328-y.

25. Scheuermeyer FX, DeWitt C, Christenson J, Grunau B, Kestler A, Grafstein E, et al. Safety of a brief emergency department observation protocol for patients with presumed fentanyl overdose. Ann Emerg Med. 2018;72(1):1-8. e1

26. Stam NC, Pilgrim JL, Drummer OH, Smith K, Gerostamoulos D. Catch and release: evaluating the safety of non-fatal heroin overdose management in the out-ofhospital environment. Clin Toxicol (Phila). 2018;1-7. https://doi.org/10.1080/15563650.2018.1478093.

27. Vilke GM, Sloane C, Smith AM, Chan TC. Assessment for deaths in out-of-hospital heroin overdose patients treated with naloxone who refuse transport. Acad Emerg Med. 2003;10(8):893-6.

28. Klar SA, Brodkin E, Gibson E, Padhi S, Predy C, Green C, et al. Notes from the field: furanyl-fentanyl overdose events caused by smoking contaminated crack cocaine - British Columbia, Canada, July 15-18, 2016. MMWR Morb Mortal Wkly Rep. 2016;65(37):1015-6.

29. Wheeler E, Marshall K, Frost T. Worlds away in a $7 X 7$ : perspectives on reaching diverse groups of people who use drugs to prevent fentanyl-related overdose in San Francisco. Oakland, CA: Harm Reduction Coalition; 2018.

30. McCall Jones C, Baldwin GT, Compton WM. Recent increases in cocaine-related overdose deaths and the role of opioids. Am J Public Health. 2017;107(3):430-2.

31. Ochoa KC, Davidson PJ, Evans JL, Hahn JA, Page-Shafer $\mathrm{K}$, Moss AR. Heroin overdose among young injection drug users in San Francisco. Drug Alcohol Depend. 2005;80(3): 297-302.

32. Nolan ML, Shamasunder S, Colon-Berezin C, et al. Increased presence of fentanyl in cocaine-involved fatal overdoses: implications for prevention. J Urban Health. 2019.

33. Lee JD, Friedmann PD, Kinlock TW, Nunes EV, Boney TY, Hoskinson RA Jr, et al. Extended-release naltrexone to prevent opioid relapse in criminal justice offenders. $N$ Engl $J$ Med. 2016;374(13):1232-42.

34. Bohnert AS, Bonar EE, Cunningham R, et al. A pilot randomized clinical trial of an intervention to reduce overdose risk behaviors among emergency department patients at risk 
for prescription opioid overdose. Drug Alcohol Depend. 2016;163:40-7.

35. Coffin PO, Santos GM, Matheson T, et al. Behavioral intervention to reduce opioid overdose among high-risk persons with opioid use disorder: a randomized controlled trial. PloS one. 2017;12(10): 0183354 . https://doi.org/10.1371 /journal.pone.0183354.
36. Coffin PO, Sullivan SD. Cost-effectiveness of distributing naloxone to heroin users for lay overdose reversal. Ann Intern Med. 2013;158:1-9.

37. National Institute on Drug Abuse. Overdose Death Rates. 2018; https://www.drugabuse.gov/related-topics/trendsstatistics/overdose-death-rates. Accessed 30 August, 2018. 